\title{
An evaluation of the environmental state of surface water quality using modified E-screen assay
}

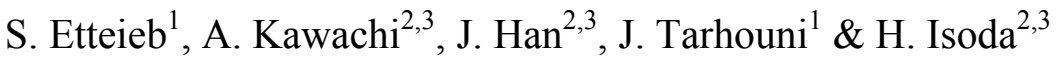 \\ ${ }^{1}$ Water science and Technology Laboratory (LSTE), \\ National Agronomic Institute of Tunisia, Tunisia \\ ${ }^{2}$ Graduate school of Life and Environmental Science, \\ University of Tsukuba, Japan \\ ${ }^{3}$ Alliance for Research on North Africa, University of Tsukuba, Japan
}

\begin{abstract}
The presence of endocrine disrupting compounds in surface water, into which, effluents from diverse anthropogenic activities (urban, industrial and agricultural) are discharged should be severely considered. In this study, the performance of Modified E-screen assay, or MCF-7 cell proliferation assay, was evaluated to test the estrogenic activity of surface water in Tunisia. To achieve this purpose, 14 location sites were sampled and analyzed for chemical parameters and biological activity. Results showed that some samples registered high Chemical Oxygen Demand values above the Tunisian guidelines, indicating the presence of high organic pollution. Then, Modified E-screen assay confirmed the presence of estrogenic compounds demonstrated by a significant proliferation level of MCF 7 cells in a dose dependent manner. Estrogenic activity in MCF7 cells was very significant ( $\mathrm{t}$-test, $\mathrm{p}<0.01$ ) in contact with the tested samples at the following concentrations $0.00001 \%, 0.0001 \%, 0.001 \%$ and $0.01 \%$. When applied to complex environmental matrices or mixture samples, in vitro estrogenicity screens help estimating the overall estrogen-mimicking load. Therefore, this study, among other E-screen studies, supports the use of MCF-7 cell proliferation as estrogenicity screen for complex samples. Such survey allows identifying the environmental risks of surface water pollution and contamination, to ensure an efficient management of water resources and the
\end{abstract}


protection of recipient water bodies. On a broader scope, the study contributed to develop local information systems to support decision-making. Keywords: modified E-screen assay, surface water, MCF-7 cells, endocrine disrupting compounds EDCs, estrogenic activity.

\section{Introduction}

Water pollution by endocrine disrupting compounds (EDCs) is one of the most critical problems concerning the environmental protection of water bodies. EDCs have been reported to interfere with the estrogenic, androgenic or thyroidal systems, and to disturb the normal function of tissues and organs [1]. EDCs are continuously being introduced into river water due to wastewater discharge of either point source pollution (WWTPs and industrial discharges...) or diffuse source pollution such as agricultural activities and livestock operations. EDCs are emerging as being of major concern for water quality, as they are associated to the increase in disturbances of wildlife reproduction and development [2].

Human health impacts that have been attributed to EDC exposure include abnormalities in human reproductive health [3], increased incidence of reproductive cancers, immunological effects and neuro developmental effects [4] and thyroid disease [3]. Many observations are consistent with the hypothesis of chemically induced feminisation of fish at sites near wastewater treatment plants (WWTPs) discharge sites. Sex ratios are skewed in various exposed fish populations, and oocytes have been found in the gonads of male fish in correlation with the occurrence of estrogenic compounds in water [5]. Numerous chemicals, such as polychlorinated biphenyls (PCBs), dioxins, flame-retardants, phthalates and pesticides, phenolic compounds and their halogenated derivatives, are environmental pollutants suspected of disrupting thyroidal homeostasis. However, previous studies $[6,7]$ showed that many conventional wastewater treatment processes are relatively ineffective in completely removing EDCs from the wastewater.

Therefore, there is a pressing need for monitoring and risk assessment of TWW and industrial wastewater to prevent harmful environmental and health impacts [8]. In order to characterise the estrogenicity of complex water samples, biological tests produce a global response to the complex mixture of chemicals without any prior knowledge of the mixture composition or its chemical properties. Modified E-screen assay has been the most widely used to evaluate estrogenic disruptions using the MCF-7 Human breast cancer cell line according to preceding studies $[9,10]$. This bioassay is sensitive and selective tool for environmental biomonitoring. Such biological assays have the major advantage of determining the overall endocrine activity of a mixture. The results of other studies $[11,12]$ confirmed that In vitro assays have advantages of being rapid, cost effective for the identification of biologically active chemicals in water sample, which promotes identification of active substances.

The aim of this study was to assess the estrogenic activity of surface water into which effluents from nearby industries and WWTPs were discharged. This survey allows identifying the environmental risks of surface water pollution and 
contamination by TWW, to ensure an efficient management of water resources and the protection of recipient water bodies. On a broader scope, the study contributed to develop local information systems to support decision-making.

\section{Materials and methods}

\subsection{Sample collection and chemical screening}

Surface water (SW) samples from a river in Tunisia all along its mainstream line and branches were collected in May 2012 (Fig. 1). These samples were collected in sterile PET bottles, stored at $4{ }^{\circ} \mathrm{C}$ and brought to the laboratory for further analysis the same day. During the field survey, some physicochemical parameters were measured in situ such as the temperature, $\mathrm{pH}$, Electrical Conductivity (EC) and Dissolved Oxygen (DO). The remaining physicochemical parameters were analyzed in the laboratory according to the International Standardization Organization and French standards as described in Table 1.

Table 1: Water parameters methods and references.

\begin{tabular}{|c|c|c|}
\hline Parameters & Method & Reference \\
\hline $\mathrm{pH}$ & Electrochemistry & NF T 90-008 \\
\hline Electrical Conductivity & Electrochemistry & NF EN 27-888 \\
\hline $\mathrm{Mg}, \mathrm{Ca}, \mathrm{Na}, \mathrm{K}$ & Atomic emission ICP & NF EN ISO 11885 \\
\hline Bicarbonates & Titrimetry & NF EN ISO 9963-1 \\
\hline Chloride & Ion chromatography & NF EN ISO 10304-2 \\
\hline nitrate & Ion chromatography & NF EN ISO 10304-1 \\
\hline sulfate & Ion chromatography & NF EN ISO 10304-1 \\
\hline
\end{tabular}

\subsection{Cells and cell maintenance}

Human breast cancer MCF-7 cells were purchased from Tsukuba, Japan and used for the following experiments. MCF-7 cells were maintained as a monolayer culture in RPMI 1640 medium (Tokyo, Japan) supplemented with $10 \%$ fetal bovine serum (Sigma, St Louis, MO, USA), 1\% penicillinstreptomycin (Lonza Walkersville, Inc., Basel, Switzerland) and incubated at $37^{\circ} \mathrm{C}, 5 \%$ of $\mathrm{CO}_{2}$. Cell passage was carried out at $80 \%$ confluence using $0.25 \%$ of trypsin.

\subsection{Modified-screen assay}

MCF-7 cells were plated into $96-$ well plates at $10^{4}$ cells $/ \mathrm{ml}$ in $100 \mu \mathrm{L}$ of medium and allowed to attach for 24 hours. Then the $14 \mathrm{SW}$ samples, which were immediately filter sterilized using a $0.45-\mu \mathrm{m}$ and $0.22-\mu \mathrm{m}$ membrane filter (Millipore), were added to the cells at concentrations of $10^{-2}, 10^{-3}, 10^{-4}, 10^{-5}$. Also, $17-\beta$-estradiol $\left(\mathrm{E}_{2}\right)$ at $29 \mathrm{nM}$ final concentration was used as positive control while phenol red free medium only as negative control. The cells were incubated in a $5 \% \mathrm{CO}_{2}$ incubator at $37^{\circ} \mathrm{C}$ for 3 days before changing medium and 
incubation for another 3 days. Then $10 \mu \mathrm{l}$ of $5 \mathrm{mg} / \mathrm{ml}$ of 3-(4,5-dimethylthiazol2-yl)-2,5-diphenyl-2H-tetrazolium bromide (MTT) was added to each well. After an incubation of $24 \mathrm{~h}, 100 \mu \mathrm{l}$ sodium dodecyl sulfate (SDS) was added to each well to completely dissolve the formazan crystals and the cells were incubated for another $24 \mathrm{~h}$. Finally, the absorbance of all experiments, which were repeated, at least three times independently was determined at $570 \mathrm{~nm}$ using a multi-detection microplate reader (Powerscan HT; Dainippon Pharmaceuticals USA Corporation, NJ, USA).

\subsection{Statistical analysis}

The statistical analysis of the mean absorbance values was performed using Student's t-test applied in Microsoft Office software (Excel 2007) to determine the significance of the means versus that of the control means. A value of $\mathrm{P}<0.05$ was considered significant $(*)$ and $\mathrm{P}<0.01$ as highly significant $(* *)$.

\section{Results and discussions}

\subsection{Water quality parameters}

The figures 2 to 4 show the spatial evolution along the river of chemical parameters, which were measured in situ, and in the laboratory for the selected samples. According to the Tunisian guidelines [13], $\mathrm{pH}$ and nitrate values are acceptable while chemical oxygen demand (COD) exceeded the threshold value for points $7(200 \mathrm{mg} / \mathrm{L})$ and $13(30 \mathrm{mg} / \mathrm{L})$ indicating the presence of a high organic pollution. According to the same guidelines chloride values for all points were higher than the threshold, except for point $5(106.5 \mathrm{mg} / \mathrm{L})$, indicating the presence of high amounts of salts and impurities [13]. Sulfate values were above the Tunisian standards as well except for points 5 and $7(73.41 \mathrm{mg} / \mathrm{L}$ and $137.91 \mathrm{mg} / \mathrm{L}$ respectively).

Point 7 registered also low level of dissolved oxygen below the standard limit fixed by the water quality evaluation system (SEQ-Eau) [14] (Fig. 4).

\subsection{Estrogenic activity identification}

Modified E-screen assay confirmed the presence of estrogenic compounds demonstrated by a significant proliferation level of MCF 7 cells in a dose dependent manner (Fig 5). Estrogenic activity in MCF 7 cells was very significant (t-test, $\mathrm{p}<0.01$ ) in contact with the tested SW samples at the following concentrations $0.00001 \%, 0.0001 \%, 0.001 \%$ and $0.01 \%$. In fact, for the highest dose of $0.01 \%$ almost all the samples registered an estrogenic potency of almost 1.5 to 1.6 times of the non-treated cell activity respectively which is close to that of the positive control (E2) (1.68 times). On one hand, the contamination of the river water with EDCs is due to the heavy pollution load discharged from raw sewage, food industries (production of dairy products and cheese, Sugar manufacture, Yeast manufacture, municipal slaughterhouse, cereal manufacture) and WWTP effluent. For instance, point 7 receives both discharges 
from industry and TWW issued from WWTP of Beja, which is not always conforming to the Tunisian standard NT 106.02. Other examples are points 5 and 8 , which receive industrial discharges (sugar manufacturer, milk factory, tomato factory, dairy products and cheese manufacture). On other hand, given the intensive agricultural activities and livestock operations conducted in our study area, EDCs may be introduced into surface water following pesticides

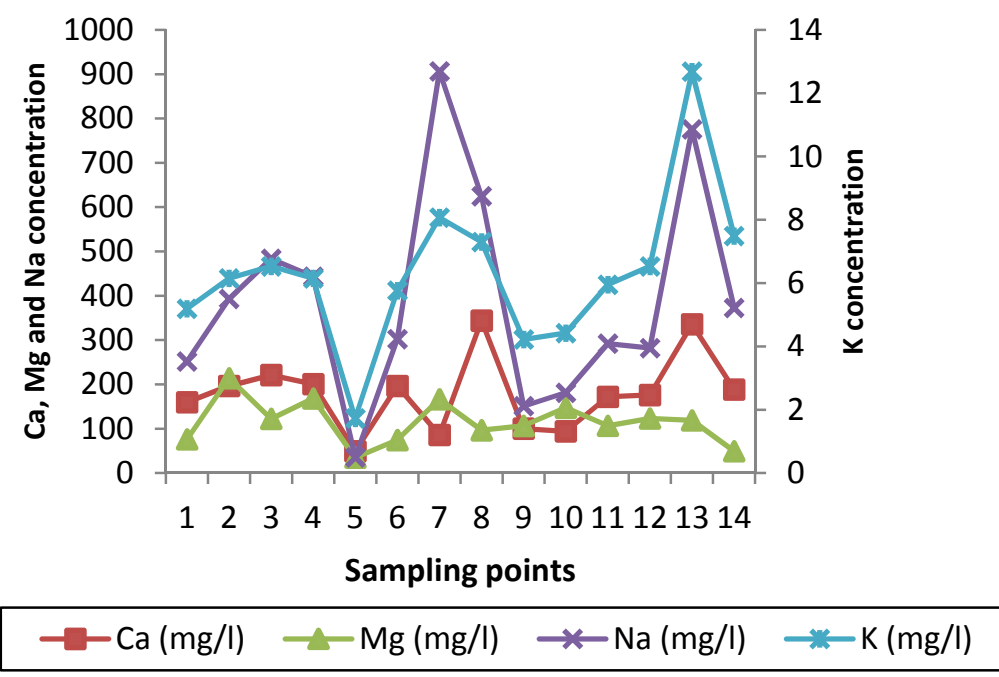

Figure 1: Spatial evolution of cations concentrations along the river.

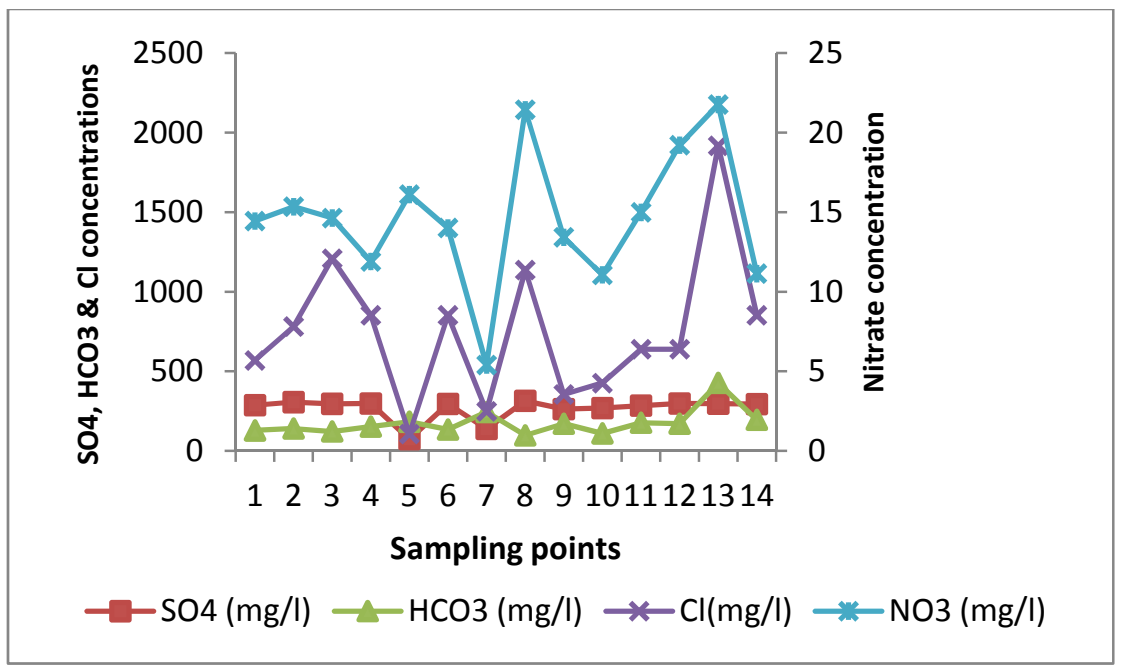

Figure 2: Spatial evolution of anions concentrations along the river. 


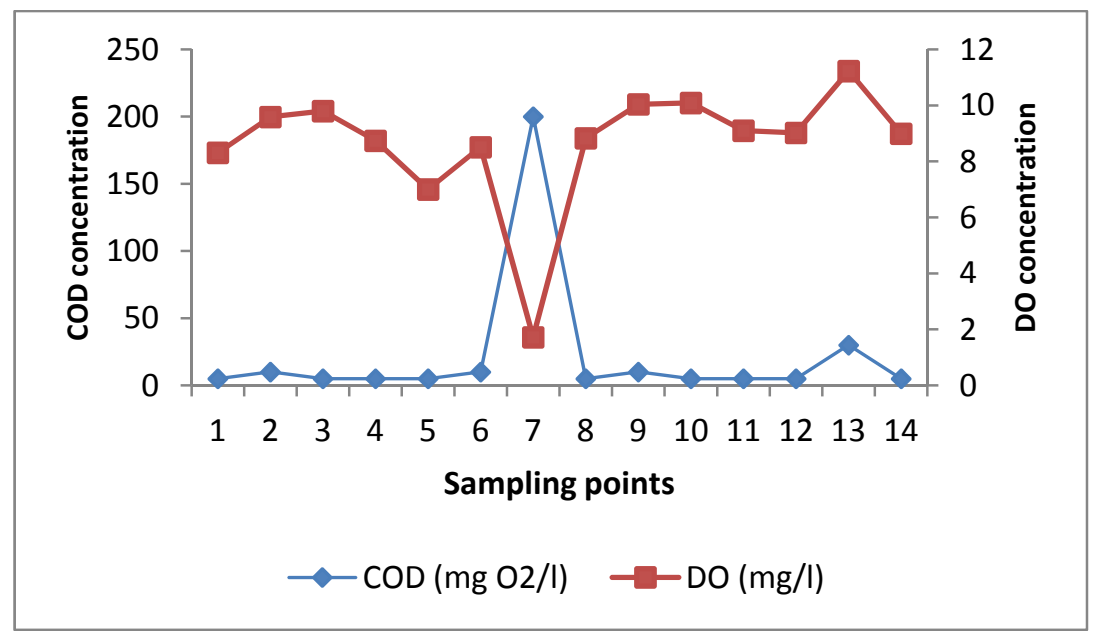

Figure 3: Spatial evolution of chemical oxygen demand (COD) and dissolved oxygen (DO) along the river.

application for agriculture production. Pesticide formulations can contain nonylphenol polyethoxylates as spreading or wetting agents [15]. Moreover estrogenic potencies may be attributed to natural and pharmaceutical estrogen and these compounds may be used by women for family planning purposes and consequently found in wastewater [16].

Furthermore, the discharge of domestic and industrial wastewater effluents are strongly suspected to be a major source of EDCs and particularly natural and synthetic estrogens and especially activated sludge which are able to produce significant amounts of free estrogens [17]. Thus previous findings, [18, 19], reported that EDCs have been detected in wastewater effluents due to their physico-chemical properties and partial resistance to biotransformation. In fact, the conventional wastewater treatment systems remove only biodegradable chemicals, microbial agents, suspended particulate matter but it has many limitations for removal of EDCs [20]. In fact, the biodegradation of estrogens is dependent on the applied wastewater treatment technology [21]. Previous studies supported the presence of estrogenic activity in treated wastewater issued from WWTPs in Tunisia such as the case of Gammarth, pilot and Mornag WWTP for which estrogenic activity was depending on the adopted treatment technology and the plant's capacity to reduce total organic carbon concentration, chemical oxygen demand and biological oxygen demand [22].

\section{Conclusions}

Water quality of the river and its tributaries deteriorates because of the huge increase of suspended solids, the high concentrations of COD, which cause very significant enrichment and eutrophication. Moreover, the results of in vitro bioassay using E-screen assay demonstrated that estrogenic activity was detected 
in river water. In fact, in vitro assay played a major role as initial screening tool for environmental samples, which outlined the necessity of further investigation using in vivo methods and/or chemical identification of active substances.

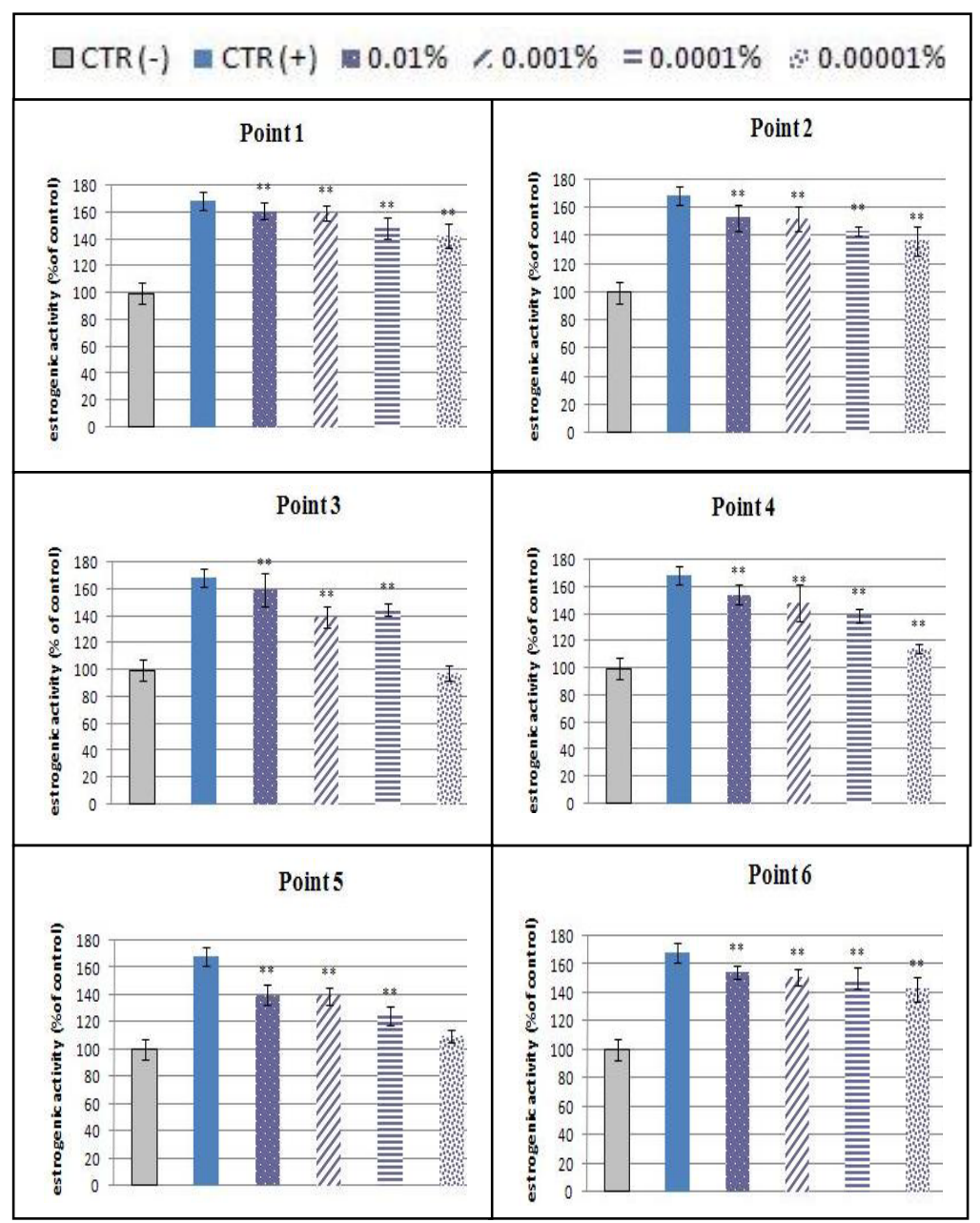

Figure 4: Relative estrogenic activities of river samples after 6 days of incubation. Medium and 17b-estradiol (E2) $(29 \mathrm{nM})$ were used as negative and positive control respectively. The results are expressed as mean $\pm \mathrm{SD}(\mathrm{n}=3),{ }^{*} \mathrm{P}<0.05, * * \mathrm{P}<0.01$ and they are presented as a percentage of control ( $100 \%$ i.e., medium only). 


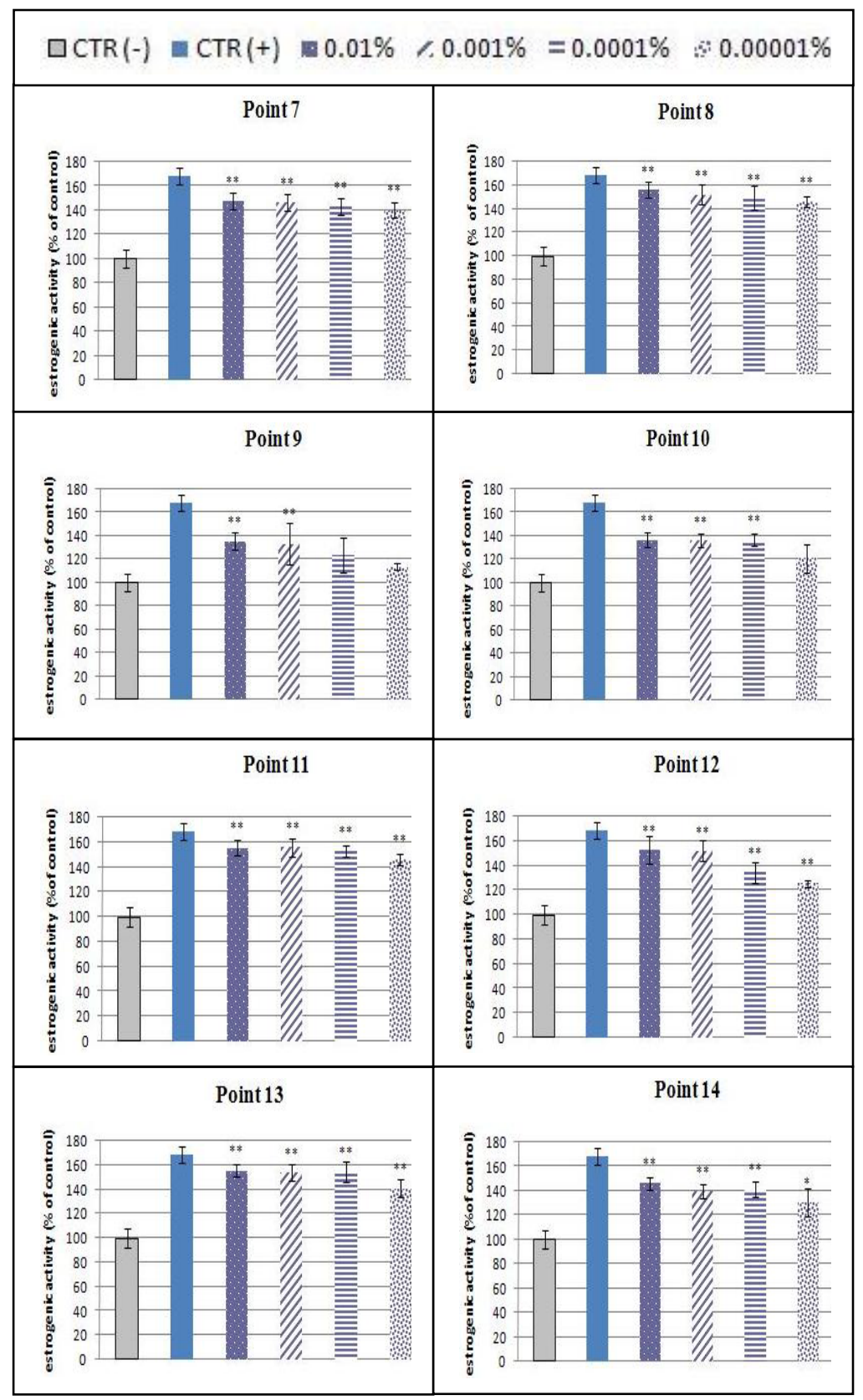

Figure 4: Continued. 
The discharge of industrial and domestic effluents into receiving water bodies in Tunisia invariably result in the generation of diverse pollutants which may be toxic to different organisms. Therefore, it is recommended that the careless disposal of industrial wastes without pretreatment should be discouraged. Also, the treatment technology adopted by WWTPs in Tunisia should be controlled and improved with continuous monitoring and surveillance is imperative in order to ensure the protection of water resources from further degradation.

\section{Acknowledgement}

This research was supported by funds from the SATREPS project for Valorization of Bio-resources in Semi-arid and Arid Land for Regional Development.

\section{References}

[1] Fatta-Kassinos, D. Kalavrouziotis, I.K. Koukoulakis, P.H. \& Vasquez, M.I., The risks associated with wastewater reuse and xenobiotics in the agroecological environment. Science of the Total Environment, 409 (19), pp. 3555-3563, 2011.

[2] Jugan, M.L. Oziol, L. Bimbot, M. Huteau, V. Tamisier-Karolak, S. Blondeau, J.P. \& Lévi, Y., In vitro assessment of thyroid and estrogenic endocrine disruptors in wastewater treatment plants, rivers and drinking water supplies in the greater Paris area (France). Science of the Total Environment, 407(11), pp. 3579-3587, 2009.

[3] Phillips, K.P. \& Foster, W.G., Key developments in endocrine disrupter research and human health. Journal of Toxicology and Environmental Health, 11 (3-4), pp. 322-344, 2008.

[4] Eskenzi, B. Marks, A.R. Bradman, A. Fenster, L. Caroline, J. Barr, D. \& Jewell, N.P., In-utero exposure to dichlorodiphenyltrichloroethane (DDT) and dichlorodiphenyl dichloroethylene (DDE) and neurodevelopment among young Mexican American children. Pediatrics, 118(1), pp. 233-241. 2006.

[5] Evans, J.S. Jackson, L. J. Habibi, H.R. \& Ikonomou, M.G., Feminization of Longnose Dace (Rhinichthys cataractae) in the Oldman River, Alberta, (Canada) Provides Evidence of Widespread Endocrine Disruption in an Agricultural Basin. Hindawi Publishing Corporation Scientica, 2012, pp. 1-11, 2012.

[6] Cirja, M. Ivashechkin, P. Schaffer, Philippe, A. \& Corvini, F. X., Factors affecting the removal of organic micropollutants from wastewater in conventional treatment plants (CTP) and membrane bioreactors (MBR). Reviews in Environmental Science and Biotechnology, 7 (1), pp. 61-78, 2008.

[7] Singhal, N. Song, Y. Johnson, A. \& Swift, S., Estrogenic Endocrine Disrupting Compounds Review and Analytical Procedures for GC-MS and 
ELISA Analyses; Prepared for Auckland Regional Council Environmental Research Technical Report - first edition, October 2009.

[8] Zegura, B. Heath, E. Cernoša, A. Filipic, M., Combination of in vitro bioassays for the determination of cytotoxic and genotoxic potential of wastewater, surface water and drinking water samples. Chemosphere, 75 (11), pp. 1453-1460, 2009.

[9] Soto, A.M. Sonnenschein, C. Chung, K.L. Fernandez, M.F. Olea, N. \& Serrano, F.O., The E-Screen assay as a tool to identify estrogens: an update on estrogenic environmental pollutants. Environmental Health Perspectives, 103 (7), pp. 113-122, 1995.

[10] Shappell, N.W., Estrogenic activity in the environment: municipal wastewater effluent, River, Ponds, and Wetlands. Journal of Environmental Quality, 35 (1), pp. 122-132, 2006.

[11] Leusch, F. D. Chapman, H.F. Van den Heuvel, M.R. Tan, B.L. Gooneratne, S.R. \& Tremblaya, L.A., Bioassay-derived androgenic and estrogenic activity in municipal sewage in Australia and New Zealand. Ecotoxicology and Environmental Safety, 65 (3), pp. 403-411, 2006.

[12] Aneck-Hahn, NH. Bornman, MS. \& deJager, C., Estrogenic activity in drinking waters from a rural area in the Waterberg District, Limpopo Province, South Africa. Water SA, 35 (3), pp. 245-251, 2009.

[13] Institut National de la Normalisation et de la Proptiété Industrielle. 1983. Tunisian standards 09.13. Surface water quality. Tunis, Tunisia.

[14] Ministère de l'Ecologie et du Développement Durable \& agences de l'eau. 2003. Water quality evaluation system (SEQ-Eau).

[15] Mrema, E.J. Rubino, F.M. Brambilla, G. Moretto, A. Tsatsakis, A.M. \& Colosio, C., Persistent organochlorinated pesticides and mechanisms of their toxicity. Toxicology, 307, pp. 74-88, 2012.

[16] Ma, M. Kaifeng, R. \& Wang, Z., Occurrence of estrogenic effects in sewage and industrial wastewaters in Beijing. China Environmental Pollution, 147(2), pp. 331-336, 2007.

[17] Baronti, C. Curini, R. D’Ascenzo, G. Di Corcia, A. \& Samperi, R., Monitoring natural and synthetic estrogens at activated sludge treatment plants and in receiving river water. Environmental Science and Technology, (24), pp. 5059-5066, 2000.

[18] Stumpf, M. Ternes, T.A. Haberer, K. \& Baumann, W., Determination of natural and synthetic estrogens in sewage plants and river water. Vom Wasser 87, pp. 251-261, 1996.

[19] Cargouet, M. Perdiz, D. Mouatassim-Souali, D. Tamisier-Karolak, A. \& Levi, S., Assessment of river contamination by estrogenic compounds in Paris area (France). Science of the Total Environment, 324 (1-3), pp. 55-66, 2004.

[20] Mahomed, S.I. Voyi, K.V.V. Aneck-Hahn, N.H. \& de Jager, C., Oestrogenicity and chemical target analysis of water from small-sized industries in Pretoria, South Africa. Water SA, 34 (3), pp. 357-364, 2008.

[21] Leusch, F.D. Chapman, H.F. van den Heuvel, M.R. Tan, B.L. Gooneratne, S.R. Tremblay, L.A., Bioassay-derived androgenic and estrogenic activity 
in municipal sewage in Australia and New Zealand. Ecotoxicology and Environmental Safety, 65 (3), pp. 403-411, 2006.

[22] Limam, A. Talorete, T.P.N. Ben Sik Ali, M. Kawano, M. Ben Rejeb Jenhani, A. Abe, Y. Ghrabi, A. \& Isoda, H., Assessment of estrogenic activity in Tunisian water and wastewater by E-screen assay. Environmental sciences, 14, pp: 43-52, 2007. 